\title{
Maternal calorie restriction modulates placental mitochondrial biogenesis and bioenergetic efficiency: putative involvement in fetoplacental growth defects in
} rats

Sylvain Mayeur, Steve Lancel, Nicolas Theys, Marie-Amélie Lukaszewski, Sophie Duban-Deweer, Bruno Bastide, Johan Hachani, Roméo Cecchelli, Christophe Breton, Anne Gabory, Laurent Storme, Brigitte Reusens, Claudine Junien, Didier Vieau and Jean Lesage

Am J Physiol Endocrinol Metab 304:E14-E22, 2013. First published 23 October 2012; doi:10.1152/ajpendo.00332.2012

You might find this additional info useful...

This article cites 37 articles, 13 of which can be accessed free at: /content/304/1/E14.full.html\#ref-list-1

Updated information and services including high resolution figures, can be found at: /content/304/1/E14.full.html

Additional material and information about AJP - Endocrinology and Metabolism can be found at: http://www.the-aps.org/publications/ajpendo

This information is current as of October 3, 2013.

AJP - Endocrinology and Metabolism publishes results of original studies about endocrine and metabolic systems on any level of organization. It is published 12 times a year (monthly) by the American Physiological Society, 9650 Rockville Pike, Bethesda MD 20814-3991. Copyright @ 2013 by the American Physiological Society. ISSN: 0193-1849, ESSN: 1522-1555. Visit our website at http://www.the-aps.org/. 


\title{
Maternal calorie restriction modulates placental mitochondrial biogenesis and bioenergetic efficiency: putative involvement in fetoplacental growth defects
} in rats

\author{
Sylvain Mayeur, ${ }^{1,2}$ Steve Lancel, ${ }^{1,3}$ Nicolas Theys,${ }^{4}$ Marie-Amélie Lukaszewski, ${ }^{1,2}$ Sophie Duban-Deweer, ${ }^{1,5}$ \\ Bruno Bastide, ${ }^{1,6}$ Johan Hachani, ${ }^{1,5}$ Roméo Cecchelli, ${ }^{1,5}$ Christophe Breton, ${ }^{1,2}$ Anne Gabory, ${ }^{7}$ \\ Laurent Storme, ${ }^{1,2}$ Brigitte Reusens, ${ }^{4}$ Claudine Junien, ${ }^{7}$ Didier Vieau, ${ }^{1,2}$ and Jean Lesage ${ }^{1,2}$ \\ ${ }^{1}$ Université Lille Nord de France, F-59000 Lille; ${ }^{2}$ Unité Environnement Périnatal et Croissance, EA4489, Equipe dénutritions \\ maternelles périnatales (Université Lille 1), Bâtiment SN4, F-59655 Villeneuve d'Ascq, France; ${ }^{3}$ Department of Physiology, \\ Faculty of Medicine, EA4484, IFR 114 IMPRT, Université Lille 2, F-59000 Lille, France; ${ }^{4}$ Université Catholique de Louvain, \\ Life Sciences Institute, Louvain-la-Neuve, Belgium; ${ }^{5}$ Laboratoire de Physiopathologie de la Barrière Hémato-Encéphalique, \\ EA2465, IMPRT-IFR 114, Université d'Artois, F-62307 Lens Cedex, France; ${ }^{6}$ Activité Physique, Muscle et Santé, EA 4345, \\ Université Lille 1, F-59655 Villeneuve d'Ascq, France; and ${ }^{7}$ Biologie du Développement et Reproduction, UMR INRA-ENVA- \\ CNRS, F-78352 Jouy en Josas, France
}

Submitted 29 June 2012; accepted in final form 23 October 2012

\begin{abstract}
Mayeur S, Lancel S, Theys N, Lukaszewski M, Duban-Deweer S, Bastide B, Hachani J, Cecchelli R, Breton C, Gabory A, Storme L, Reusens B, Junien C, Vieau D, Lesage J. Maternal calorie restriction modulates placental mitochondrial biogenesis and bioenergetic efficiency: putative involvement in fetoplacental growth defects in rats. Am J Physiol Endocrinol Metab 304: E14-E22, 2013. First published October 23, 2012; doi:10.1152/ajpendo.00332.2012._- Low birth weight is associated with an increased risk for developing type 2 diabetes and metabolic diseases. The placental capacity to supply nutrients and oxygen to the fetus represents the main determiner of fetal growth. However, few studies have investigated the effects of maternal diet on the placenta. We explored placental adaptive proteomic processes implicated in response to maternal undernutrition. Rat term placentas from $70 \%$ food-restricted (FR30) mothers were used for a proteomic screen. Placental mitochondrial functions were evaluated using molecular and functional approaches, and ATP production was measured. FR30 drastically reduced placental and fetal weights. FR30 placentas displayed 14 proteins that were differentially expressed, including several mitochondrial proteins. FR30 induced a marked increase in placental mtDNA content and changes in mitochondrial functions, including modulation of the expression of genes implicated in biogenesis and bioenergetic pathways. FR30 mitochondria showed higher oxygen consumption but failed to maintain their ATP production. Maternal undernutrition induces placental mitochondrial abnormalities. Although an increase in biogenesis and bioenergetic efficiency was noted, placental ATP level was reduced. Our data suggest that placental mitochondrial defects may be implicated in fetoplacental pathologies.
\end{abstract}

placenta; proteomic; mitochondria; fetal growth; rat

FETAL GROWTH IS DEPENDENT primarily upon the nutritional, hormonal, and metabolic environment provided by the mother (13). A wartime famine study in Holland first showed that a low food intake during pregnancy produces smaller-size infants at birth (1). Growing evidence indicates that being of small size at birth from malnutrition is associated with an increased risk of developing type 2 diabetes, metabolic syn-

Address for reprint requests and other correspondence: J. Lesage, Unité Environnement Périnatal et Croissance, Equipe dénutritions maternelles périnatales, Université de Lille 1, Bâtiment SN4, F-59655 Villeneuve d'Ascq, France (e-mail: jean.lesage@univ-lille1.fr). drome, and cardiovascular disease $(2,26,30)$. However, the physiopathological effects acting in utero on the programming of the offspring's metabolic profile remain confused and may implicate numerous molecules and physiological systems. Fetal growth is a complex process that depends on the genotype and epigenotype of both the fetus and parents, the availability of nutrients and oxygen to the fetus, and a variety of growth factors and proteins of maternal and fetoplacental origin. However, along with pregnancy, the placental capacity to supply an adequate amount of nutrients and oxygen to the fetus represents one of the main determiners of the fetal growth (12). Evidence that the placenta is a programming agent for cardiovascular diseases is accumulating $(14,33,35)$. Because the placenta is the primary communication and nutrient acquisition organ for the fetus and presumably acts to maintain fetal homeostasis, it is also an appropriate organ to examine how differences in maternal food consumption are sensed by the developing offspring (14). Placental function follows a carefully orchestrated developmental cascade during gestation. Disruption of this cascade can lead to abnormal development of the placental vasculature of the trophoblast. Both its development and ongoing functions can be dynamically regulated by environmental factors, including the maternal nutrient status $(4,14)$. Because of the significant and increasing proportion of women eating inadequately during pregnancy and the fact that such disturbance may compromise adult health in offspring, it is urgent that we better understand how the placenta elaborates adaptative responses to maternal diet. In the present study, we investigated the ways in which maternal food restriction might influence the placental proteome of rat term placentas. In this study, we observed diet-specific differential expression of a limited number of placental proteins, and we noted that importants part of them were from mitochondrial origin. Because few studies have investigated the physiology of mitochondria in the placenta, we studied using molecular and functional analyses the effect of maternal undernutrition on these organelles. Our data provide novel evidence for a critical role of defective placental mitochondrial function in the pathology of fetal growth restriction associated with maternal suboptimal nutrition, suggesting that mitochondria in this organ may exert 
a critical role in the fetoplacental development and putatively in the offspring's metabolic profile programming.

\section{MATERIALS AND METHODS}

Animal model. Experiments were conducted in accordance with the principles of laboratory animal care of the European Communities (86/609/EEC). Animal use accreditation by the French Ministry of Agriculture (no. 04860) was granted to our laboratory for experimentation with rats. Adult Wistar rats $(280 \mathrm{~g})$ were purchased from Janvier (L'Arbresle, France) and housed with a controlled light cycle (12:12-h light-dark cycle, lights on at 7 AM) and temperature (22 \pm $2^{\circ} \mathrm{C}$ ), with free access to chow (SAFE 04, containing $16 \%$ protein, $3 \%$ fat, and $60 \%$ carbohydrates; UAR) and tap water. After acclimation, females were mated with a male. Embryonic day 0 (E0) was defined the following day if spermatozoa were found in vaginal smears. Pregnant females were transferred to individual cages. Two groups of pregnant rats were studied. In the control (C) group $(n=9)$, dams were fed ad libitum during gestation. In the food-restricted group (FR30 group; $n=9$ ), females received $30 \%$ of the food intake of control mothers, which has been determined previously in pilot studies (7.2 g/day of food from E0 to E21).

Plasma and tissue collection. At E21, mothers were rapidly weighed and euthanized between 9 and 10 AM. The placentas and fetuses were collected by caesarean section; they were weighed, and the sex was determined. For each measurement, only male fetuses and their placentas were used. For fetal and placental parameters litters were averaged, and then these averages were used for comparisons. Placentas were cut in two pieces and were frozen in liquid $\mathrm{N}_{2}$. Maternal and fetal blood glucose level was determined using a glucometer (Glucotrend 2; Roche Diagnostics), and samples were collected and centrifuged at 4,000 g for $10 \mathrm{~min}$ at $4^{\circ} \mathrm{C}$. Plasma aliquots were stored at $-20^{\circ} \mathrm{C}$. Metabolic parameters (triglyceride and cholesterol plasma levels) were obtained using an automatic biochemistry analyzer (VetTest; IDEXX).

Sample preparation for two-dimensional analysis. Frozen halves of male placentas from each litter were processed individually by grinding. Frozen powders from each placenta were pooled in each litter and thawed by adding $800 \mu \mathrm{l}$ of cold lysis buffer [0.3\% SDS, $1 \times$ protease inhibitor mix (Amersham Bioscience), and $50 \mathrm{mM}$ Tris at $\mathrm{pH}$ 7.4] and sonicated for $30 \mathrm{~s}$ (Vibracell; Sonics \& Material). Sonicated solutions were centrifuged at $10,000 \mathrm{~g}$ for $10 \mathrm{~min}$ at $4^{\circ} \mathrm{C}$. Supernatants were collected and treated for $30 \mathrm{~min}$ at $30^{\circ} \mathrm{C}$ with 100 units of Benzonase nuclease (E8263; Sigma-Aldrich). Tubes were centrifuged at 10,000 g for $10 \mathrm{~min}$ at $4^{\circ} \mathrm{C}$. Supernatants were collected, and protein concentrations were measured using a Bradford-based protein assay (DC protein assay; Bio-Rad) with BSA as standard.

Two-dimensional gel electrophoresis. Placental lysates from each litter were pooled to constitute the two experimental groups (FR30 and controls). For the first-dimension separation, $500 \mu \mathrm{g}$ of sample protein was diluted in $500 \mu \mathrm{l}$ of buffer $\{8 \mathrm{M}$ urea, 2\% 3-[(3cholamidopropyl)dimethylammonio]-1-propanesulfonate, $10 \mathrm{mM}$ DTT, $0.2 \%$ carrier ampholytes $\}$ and loaded onto an immobilized $\mathrm{pH}$ gradient (IPG) strip (Immobiline Drystrip pH 3-10 NL, 18 cm; GE Healthcare) by overnight passive in-gel rehydratation. Isoelectric focusing within the strips was performed at $20^{\circ} \mathrm{C}$ with an Ettan IPGphor system (Amersham) using a total of $80,000 \mathrm{~V} / \mathrm{h}$, with a maximum of $8,000 \mathrm{~V}$. For the second dimension separation, the IPG strips were soaked for $2 \times 15 \mathrm{~min}$ in $5 \mathrm{ml}$ of equilibration buffer (6 M urea, 30\% glycerol, 2\% SDS, 1\% DTT, and 0.375 M Tris, pH 8.8 ), followed by $15 \mathrm{~min}$ in $5 \mathrm{ml}$ of a second equilibration buffer (with $2.5 \%$ iodoacetamide substituted for $1 \%$ DTT), and positioned against $15 \%$ SDS duracryl gels in an Ettan DALTsix (GE Healthcare Life Sciences) at $12 \mathrm{~mA} / \mathrm{gel}$ for $20 \mathrm{~min}$ and then $45 \mathrm{~mA} / \mathrm{gel}$ until the bromophenol blue dye front reached the bottom of the gel. Gels were fixed, and resolved protein spots were visualized with silver nitrate staining.

Image analysis of two-dimensional gels. Image acquisitions were performed with a calibrated Umax Scanner (Amersham Biosciences, Orsay, France) using the Labscan 3.0 software. Digitized images were stored in the Tagged Image File format. Scanned images were compared using Progenesis SameSpots software (Nonlinear Dynamics, Durham, NC) for detection of differentially expressed spots. Spot matching was performed automatically and then manually. The soft-

Table 1. Parameters of the primers used for $q R T-P C R$

\begin{tabular}{|c|c|c|c|c|c|c|c|c|c|c|c|c|c|c|c|c|c|c|}
\hline \multirow{3}{*}{$\frac{\text { Gene }}{\text { Gapdh }}$} & \multicolumn{15}{|c|}{ Primer Sequence } & \multirow{2}{*}{$\begin{array}{c}\text { Amplification } \\
\text { Temperature } \\
\left({ }^{\circ} \mathrm{C}\right)\end{array}$} & \multirow{2}{*}{$\begin{array}{l}\text { Amplicon } \\
\text { Size }\end{array}$} & \multirow{2}{*}{ Genbank No. } \\
\hline & \multicolumn{8}{|c|}{ Forward } & \multicolumn{7}{|c|}{ Reverse } & & & \\
\hline & $5^{\prime}-\mathrm{TGA}$ & CTC & TAC & $\mathrm{CCA}$ & CGG & CAA & GTT-3 & & $5^{\prime}$-CTT & CCC & ATT & CTC & AGC & CTT & GACT-3' & 60 & 52 & NM_017008 \\
\hline Ppib & $5^{\prime}$-TTT & CGG & $\mathrm{CAA}$ & AGT & TCT & GGA & AGG & CA-3' & $5^{\prime}$-CTT & GCC & $\mathrm{ACA}$ & GTC & TAC & AAT & GAT CAC A-3' & 60 & 109 & NM_022536 \\
\hline Hprt1 & $5^{\prime}-G T G$ & TCA & TCA & GCG & AAA & GTG & GA-3' & & $5^{\prime}-\mathrm{ATG}$ & GCC & $\mathrm{ACA}$ & GGA & CTA & GAA & CG-3' & 60 & 123 & NM_012583 \\
\hline Aplnr & $5^{\prime}-\mathrm{CCT}$ & TCA & TCA & TCA & TGC & TGA & $\mathrm{CCT}$ & GTT A-3' & $5^{\prime}-\mathrm{GGT}$ & GGT & AAG & GCA & TCC & AGC & ACA $\quad$ G- $3^{\prime}$ & 64 & 159 & NM_031349 \\
\hline$m t-\mathrm{Col}$ & $5^{\prime}-\mathrm{ATC}$ & TAT & AGG & AGC & AGT & ATT & CGC & $C-3^{\prime}$ & $5^{\prime}-\mathrm{TGG}$ & GCT & TTT & GCT & CAT & GTG & TC-3' & 64 & 96 & YP_665631 \\
\hline$m t-C o 2$ & $5^{\prime}-\mathrm{TGA}$ & GCC & ATC & $\mathrm{CCT}$ & TCA & CTA & GG-3' & & $5^{\prime}$-TGA & GCC & GCA & $\mathrm{AAT}$ & TTC & AGA & G-3' & 60 & 120 & YP_665632 \\
\hline Ppargcla & $5^{\prime}-G T T$ & $\mathrm{CCC}$ & GAT & CAC & CAT & $\mathrm{ATT}$ & $\mathrm{CCA}-3$ & & $5^{\prime}-\mathrm{TGT}$ & GCG & GTG & TCT & GTA & GTG & GC-3' & 60 & 104 & NM_031347 \\
\hline Nrf1 & $5^{\prime}-\mathrm{CTC}$ & $\mathrm{ACC}$ & CTC & CAA & ACC & CAA & CC- $3^{\prime}$ & & $5^{\prime}-\mathrm{CCA}$ & GCG & CAG & $\mathrm{ACT}$ & CCA & GGT & $C-3^{\prime}$ & 60 & 110 & XM_231566 \\
\hline Tfam & $5^{\prime}-G G C$ & GAA & GTG & ATC & TCA & TCC & G-3' & & $5^{\prime}$-TTC & TTG & TGC & $\mathrm{CCA}$ & ATC & $\mathrm{CCA}$ & $\mathrm{A}-3^{\prime}$ & 60 & 101 & NM_031326 \\
\hline$m t-N d 4 l$ & $5^{\prime}-\mathrm{TCC}$ & CAA & TTA & $\mathrm{CCA}$ & TTC & TAG & TTT & $\mathrm{T}-3^{\prime}$ & $5^{\prime}-\mathrm{AGG}$ & TTT & TGT & ACG & TAG & TCT & GTT CCG T-3' & 60 & 103 & YP_665637 \\
\hline$m t-A t p 6$ & $5^{\prime}-\mathrm{TCG}$ & СТT & CGC & TTT & GTA & СTC & TCT & T-3' & $5^{\prime}-G G T$ & CAG & CAG & TCT & CTG & TGC & ATT T-3' & 60 & 122 & YP_665634 \\
\hline Ucpl 1 & $5^{\prime}-\mathrm{AAG}$ & ACA & GAA & GGA & TTG & CCG & AAA & $C-3^{\prime}$ & $5^{\prime}-\mathrm{ACT}$ & GGG & ACC & TAC & AAT & GCT & TAC A-3' & 60 & 286 & NM_012682 \\
\hline Ucp2 & $5^{\prime}-\mathrm{CTC}$ & $\mathrm{CCA}$ & ATG & TTG & $\mathrm{CCC}$ & GAA & $\mathrm{A}-3^{\prime}$ & & $5^{\prime}-\mathrm{GAG}$ & GTC & GTC & TGT & CAT & GAG & GTT G-3' & 60 & 144 & NM_019354 \\
\hline Ucp3 & $5^{\prime}-G G G$ & $\mathrm{ACT}$ & TGG & CCC & $\mathrm{AAC}$ & ATC & $\mathrm{ACA}$ & $\mathrm{A}-3^{\prime}$ & $5^{\prime}-\mathrm{CCA}$ & CCA & CCG & TGG & CAC & AGA & AAC C-3' & 60 & 163 & NM_013167 \\
\hline Slc25a27 & $5^{\prime}-\mathrm{TTT}$ & TAG & CCA & ATC & CAA & CTG & $\mathrm{ACC}$ & TA-3' & $5^{\prime}-\mathrm{TAT}$ & TCA & $\mathrm{CCA}$ & GTG & CTG & CTC & TTT GT-3' & 60 & 186 & NM_053500 \\
\hline Slc25a14 & $5^{\prime}-\mathrm{GTT}$ & $\mathrm{CCG}$ & СTT & TAA & GCC & $\mathrm{ATG}$ & AGA & TG-3' & $5^{\prime}-\mathrm{CGA}$ & TAC & TCT & GAC & CTT & GGA & CTT GC-3' & 60 & 119 & NM_053501 \\
\hline Slc25a4 & $5^{\prime}-\mathrm{CCC}$ & TCT & GCT & TCG & TCT & $\mathrm{ACC}$ & $\mathrm{CAC}$ & TG-3' & $5^{\prime}-\mathrm{GGG}$ & CAA & TCA & TCC & AGC & TCA & CAA TA-3' & 60 & 273 & NM_053515 \\
\hline Slc25a5 & $5^{\prime}-G G A$ & СTT & СTT & GGC & TGG & TGG & AGT & GG-3' & $5^{\prime}-\mathrm{TAT}$ & CTG & CCG & TGA & TTT & GCT & TGC TG-3' & 60 & 116 & NM_057102 \\
\hline
\end{tabular}

Ppib (CycloB), peptidylprolyl isomerase B; Hprt1, hypoxanthine phosphoribosyltransferase I; Aplnr, apelin receptor; mt-Col cytochrome $c$ oxidase I, mitochondrial; $m t$-Co2, cytochrome $c$ oxidase II, mitochondrial; Ppargcla $($ Pgc-1 $\alpha)$, peroxisome proliferator-activated receptor- $\gamma$ coactivator-1 $\alpha$; Nrfl, nuclear respiratory factor 1; Tfam mitochondrial transcription factor A; $m t$-Nd4l, NADH dehdrogenase 4L, mitochondrial; $m t$-Atp6, ATP synthase 6, mitochondrial; Ucp 1, uncoupling protein 1; Ucp2, uncoupling protein 2; Ucp3, uncoupling protein 3; Slc25a27 (Ucp4), solute carrier family 25, member 27; Slc25a14 (Bmcp1), brain mitochondrial uncoupling 1; Slc25a4 (Ant1), solute carrier family 25 (mitochondrial carrier; adenine nucleotide translocator), member 4; Slc25a5 (Ant2), solute carrier family 25 (mitochondrial carrier; adenine nucleotide translocator), member 5. 
Table 2. Maternal and fetal parameters

\begin{tabular}{lccc}
\hline \hline & Control & FR30 & $P$ Value \\
\hline Maternal weight, g & $444 \pm 8$ & $270 \pm 11$ & $<0.001$ \\
Maternal blood glucose, mmol/1 & $4.87 \pm 0.202$ & $4.02 \pm 0.172$ & 0.008 \\
Maternal blood triglycerides, g/l & $1.86 \pm 0.347$ & $0.73 \pm 0.211$ & 0.017 \\
Maternal cholesterol, g/l & $0.771 \pm 0.099$ & $0.564 \pm 0.049$ & 0.011 \\
Litter size & $12.1 \pm 1.68$ & $11.6 \pm 0.72$ & $\mathrm{NS}$ \\
Male/female ratio & $1.01 \pm 0.181$ & $1.1 \pm 0.127$ & $\mathrm{NS}$ \\
Fetal weight, g & $5.56 \pm 0.073$ & $3.97 \pm 0.164$ & $<0.001$ \\
Fetal height, mm & $45.9 \pm 0.433$ & $42.7 \pm 0.615$ & $<0.001$ \\
Fetal blood glucose, mmol/1 & $7.44 \pm 0.778$ & $4.33 \pm 0.522$ & $<0.001$ \\
Fetal blood triglycerides, g/l & $0.467 \pm 0.079$ & $0.382 \pm 0.060$ & $\mathrm{NS}$ \\
Fetal blood cholesterol, g/l & $0.476 \pm 0.084$ & $0.362 \pm 0.040$ & $\mathrm{NS}$ \\
Placental weight, mg & $592 \pm 17$ & $443 \pm 19$ & $<0.001$ \\
Fetus/placental ratio & $9.44 \pm 0.25$ & $9.06 \pm 0.54$ & $\mathrm{NS}$ \\
\hline
\end{tabular}

Values are means \pm SE. Control group: $n=9$; food-restricted group (FR30): $n=8$.

ware was programmed to select significant spots (ANOVA with $P<$ 0.05 and cutoff spots with a significant $\geq 1$.4-fold difference).

In-gel trypsin digestion. Differentially expressed spots were excised. Destaining of excised pieces was performed with two 20-min washes with $1.6 \%$ sodium thiosulfate and potassium ferricyanate. Pieces were washed with water until the gels were clear. Following dehydration with $100 \%$ acetonitrile, $10 \mu \mathrm{l}$ of $7.5 \mathrm{ng} / \mu \mathrm{l}$ sequencing grade trypsin (Promega) was added to gel pieces for $5 \mathrm{~min}$ at $4^{\circ} \mathrm{C}$. The supernatant was removed, and the pieces were incubated overnight at $37^{\circ} \mathrm{C}$ with $30 \mu \mathrm{l}$ of $20 \mathrm{mM}$ sodium bicarbonate, $\mathrm{pH}$ 8. Supernatants containing tryptic peptides were extracted for protein identification.
Matrix-assisted laser desorption ionization-time-of-flight/time-offlight analysis. The matrix-assisted laser desorption ionization target plate (MALDI) (AnchorChip; Bruker Daltonics) was covered with extracted peptides mixed up with $\alpha$-cyano-4-hydroxy-cinnamic acid matrix $(0.3 \mathrm{mg} / \mathrm{ml}$ in acetone-ethanol, 3:6 vol $/ \mathrm{vol})$. The molecular mass measurements were performed in automatic mode using FlexControl 2.2 software on an Ultraflex II time-of-flight/time-of-flight (TOF/TOF) instrument and in the reflectron mode for MALDI-TOF peptide mass fingerprint (PMF) or LIFT mode for MALDI-TOF/TOF peptide fragmentation fingerprint (PFF). External calibration over a 1,000- to 3,200-mass range was performed using the $[\mathrm{M}+\mathrm{H}]^{+}$ monoisotopic ions of bradikinin 1-7, angiotensin I, angiotensin II, substance $\mathrm{P}$, bombesin, and adrenocorticotropic hormone [ACTH 1-17 and ACTH 18-39 (CLIP)] from a peptide calibration standard kit (Bruker Daltonics). Briefly, an accelerating voltage of $25 \mathrm{kV}$, a reflector voltage of $26.3 \mathrm{kV}$, and a pulsed ion extraction of $160 \mathrm{~ns}$ were used to obtain the MS spectrum. Each spectrum was produced by accumulating data from 800 laser shots. A maximum of four precursor ions per sample were chosen for LIFT-TOF/TOF-MS/MS analysis. Precursor ions were accelerated to $8 \mathrm{kV}$ and selected in a timed ion gate. Metastable ions generated by laser-induced decomposition were further accelerated by $19 \mathrm{kV}$ in the LIFT cell and their masses measured in reflectron mode. Peak lists were generated from MS and MS/MS spectra using Flexanalysis 2.4 software (Bruker Daltonics). Database searches through Mascot 2.3 (Matrix Science, London, UK), using combined PMF and PFF data sets, were performed in the UniProt 2011_02 database via ProteinScape 2.1 (Bruker Daltonics). A mass tolerance of $75 \mathrm{ppm}$ and one missing cleavage site for PMF and MS/MS tolerance of $0.5 \mathrm{Da}$ and one missing cleavage site for MS/MS search were allowed. Carbamidomethylation of cysteine and oxidation of methionine residues were also considered. Relevance of protein
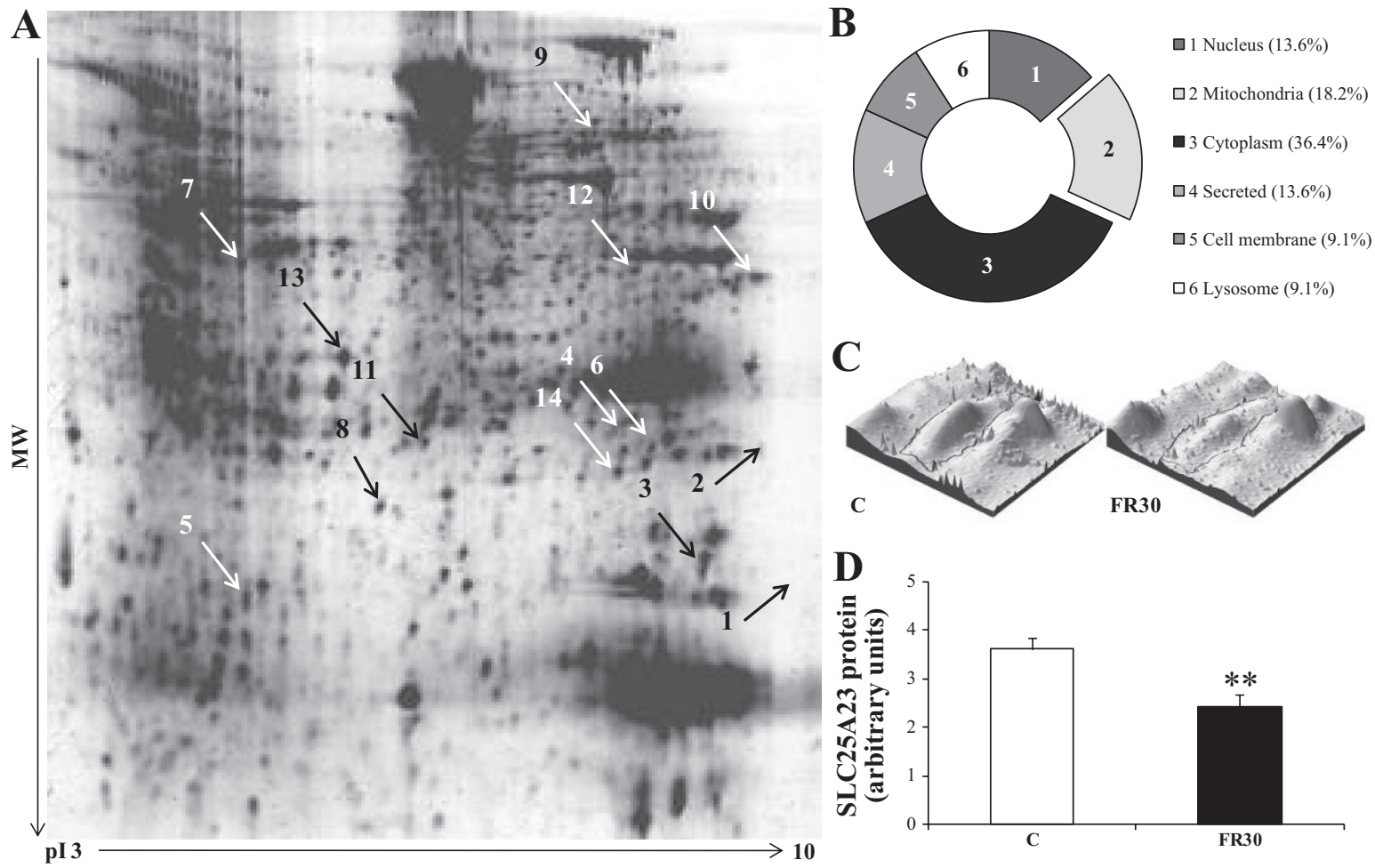

Fig. 1. Two-dimensional gel analyses of proteins from control and food-restricted (FR30) placenta. A: representative image of 2-dimensional gel of placental protein profiles in rat separated by isolectric point $(p I)$ on a pH 3-10 gradient strip and then molecular weight (MW) on a 15\% SDS-PAGE gel. Directions of arrows indicate differential expression in FR30 group. B: classification of differentially expressed proteins according to their cellular localization. $C$ : representative quantitative 3-dimensional view of the SLC25A23 protein (spot $\mathrm{n}^{\circ} 5$ ) used for confirmation by Western blotting. $D$ : confirmation of differential SLC25A23 expression in control $(n=7)$ and FR30 $(n=7)$ groups by Western blotting. $* * P<0.01$ vs. FR30 group. 
identities was judged according to the probability-based Mowse score, calculated with a $P$ value of 0.05 .

Western blot analysis. Proteins $(30 \mu \mathrm{g})$ from placental lysates used for the two-dimensional gels were separated on 12\% SDS-PAGE and transferred electrophoretically onto a nitrocellulose membrane. Blots were blocked with 5\% skimmed milk in Tris-buffered saline solution containing $0.1 \%$ Tween-20 and probe with the following antibodies: goat anti-rat SLC25A23 (sc-162206; Santa Cruz Biotechnology), MitoProfile Total OXPHOS Rodent WB Antibody Cocktail (MS604; Mitosciences), mouse anti- $\alpha$-tubulin (T6199; Sigma-Aldrich), or rabbit anti-rat GAPDH (2118S; Cell signaling). Blots were incubated with primary antibody (SLC25A23 at 1:400 dilution, OXPHOS at $1: 1,000$ dilution, $\alpha$-tubulin at 1:2,000 dilution, or GAPDH at 1:5,000 dilution) overnight at $4{ }^{\circ} \mathrm{C}$ and then incubated with secondary antibody [SLC25A23: anti-goat IgG peroxidase conjugate at 1:50,000 dilution (A5420; Sigma-Aldricht); OXPHOS and $\alpha$-tubulin: goat anti-mouse $\operatorname{IgG}(\mathrm{H}+\mathrm{L})$-horseradish peroxidase (HRP) conjugate at 1:5,000 and 1:35,000 dilution, respectively (172-1,011; Bio-Rad); GAPDH: goat anti-rabbit $\operatorname{IgG}(\mathrm{H}+\mathrm{L})$-HRP conjugate at 1:10,000 (172-1,019, Bio-Rad)] for $1 \mathrm{~h}$ at room temperature. Blots were exposed using a chemiluminescent detection method (Western lightning plus ECL; Perkin-Elmer). A densitometric analysis was conducted using GS-800 Imaging densitometer and QuantityOne Software (Bio-Rad). Expressions were normalized with both GAPDH and $\alpha$-tubulin.

mtDNA measurement. A quarter of placenta was mixed with $1 \mathrm{ml}$ of lysis buffer [100 $\mu \mathrm{g}$ of proteinase K (Sigma-Aldrich), $100 \mathrm{mM}$ Tris, $\mathrm{pH} 8,0.2 \%$ SDS, $5 \mathrm{mM}$ EDTA, and $200 \mathrm{mM} \mathrm{NaCl}]$ and incubated overnight at $55^{\circ} \mathrm{C}$. Placentas were grinded and centrifuged at $13,000 \mathrm{~g}$ for $20 \mathrm{~min}$ at room temperature. Supernatants were collected and mixed with phenol $\mathrm{pH}$ 8/chloroform (vol/vol). Tubes were centrifuged at $13,000 \mathrm{~g}$ for $10 \mathrm{~min}$ at $18^{\circ} \mathrm{C}$. Supernatants $(150$ $\mu \mathrm{l})$ were collected, and sodium acetate $(0.1 \mathrm{~V})$ with cold ethanol was added to precipitate DNA. After $1 \mathrm{~h}$, tubes were centrifuged at 13,000 $g$ for $10 \mathrm{~min}$ at $4^{\circ} \mathrm{C}$, and DNA was dissolved with $50 \mu \mathrm{l}$ of water. Quantification of mitochondrial DNA (mtDNA; mean of $m t-C o l$ and $m t$-Co2 genes) levels relative to nuclear DNA (nDNA; Aplnr gene) was performed using a quantitative PCR (qPCR) method. qPCR was performed with a SYBR Green technology (Roche) and a LightCycler 480 (Roche), following Table 1 and the manufacturer's instructions. Each sample was evaluated in duplicate. Analysis of DNA level was carried out by first using the determination of the threshold cycle $\mathrm{C}_{\mathrm{T}}$ for each reaction corrected by the efficiency. The amount of target relative to a calibrator was computed by the $2^{-\Delta C_{\mathrm{T}}}$ method, as validated previously (23).

Quantitative RT-PCR. Total RNAs were isolated, as described previously (23), from the second half of placenta used for the proteomic analysis, and quantitative RT-PCR (qRT-PCR) was performed with a Light Cycler 480 SYBR Green I master and a LightCycler 480 (Roche), following the Table 1 and the manufacturer's instructions. Three different housekeeping genes (Gapdh, Ppib, and Hprt l) were used for the normalization.

Placental mitochondria isolation and high-resolution respirometry. For respirometry analysis, a series of placentas was selected and compared with the data of the Table 1. For each mother, mitochondria isolation was performed on two pools of two selected placentas. For respiratory measurement, each pool was quantified in duplicate on separate chambers. Each mean value was obtained from a total of $n=$ 32 placentas from eight control mothers and $n=24$ placentas from six FR30 mothers. The average of values found in each litter was calculated and used for the statistical analysis. Placentas were placed in isolation buffer A containing $300 \mathrm{mM}$ sucrose, $5 \mathrm{mM}$ TES, and 0.2 mM EGTA, pH 7.2, at $4^{\circ} \mathrm{C}$. Placentas were then minced and homogenized by the use of a Kontes tissue grinder. After centrifugation ( 800 $g$ for $7 \mathrm{~min}$ ), the supernatant was centrifuged at $8,800 \mathrm{~g}$ for $7 \mathrm{~min}$. Mitochondrial pellet was suspended in $1 \mathrm{ml}$ of buffer $A$ and centrifuged at $8,800 \mathrm{~g}$ for $7 \mathrm{~min}$. Protein concentration was determined according to the Bradford method. Mitochondrial pellet was sus-

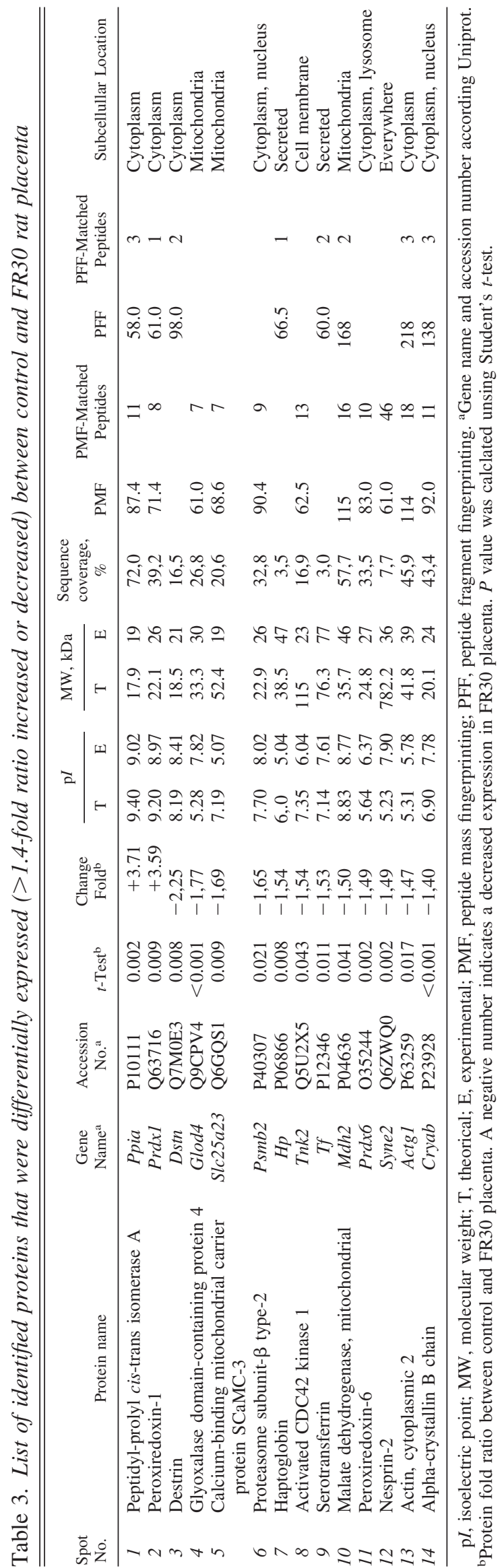


A

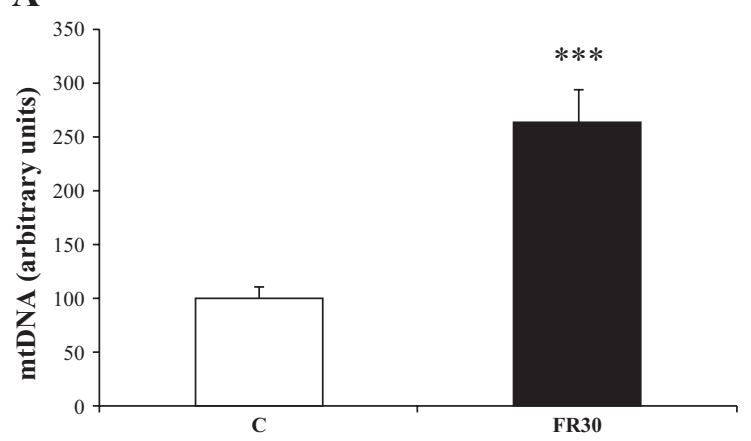

B

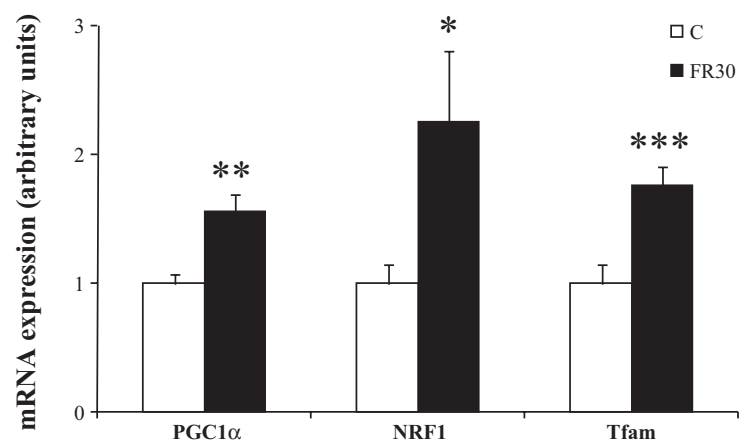

Fig. 2. Measurement of mitochondrial biogenesis indicators. A: relative quantification of mitochondrial DNA (mtDNA) content by real-time quantitative PCR (qPCR) analysis in control $(n=7)$ and FR30 $(n=7)$ placenta. $B$ : relative quantification of PGC-1 $\alpha$, nuclear respiratory factor 1 (NRF1), and mitochondrial transcription factor (TFAM) mRNA expression by RT-qPCR in control $(\mathrm{C} ; n=8-9)$ and FR30 $(n=9)$ groups. ${ }^{*} P<0.05$ vs. FR30 group; $* * P<$ 0.01 vs. FR30 group; $* * * P<0.001$ vs. FR30 group.

pended in buffer $B$, pH 7.1, containing $100 \mathrm{mM}$ sucrose, $20 \mathrm{mM}$ HEPES, $1 \mathrm{mM} \mathrm{KH} \mathrm{PO}_{4}, 20 \mathrm{mM}$ taurine, $3 \mathrm{mM} \mathrm{MgCl} 2.6 \mathrm{H}_{2} \mathrm{O}, 60 \mathrm{mM}$ K-MES, $0.5 \mathrm{mM}$ EGTA, and $1 \mathrm{~g} / \mathrm{l} \mathrm{BSA}$-fraction V.

For high-resolution respirometry, 2,250 $\mu \mathrm{g}$ of protein from mitochondrial fraction was measured at $25^{\circ} \mathrm{C}$ in a two-chamber respirometer (Oroboros O2k oxygraph; Oroboros, Innsbruck, Austria) containing a volume of $2 \mathrm{ml}$ of buffer $B$. Respiration state 1 was determined. Respiratory state 4 (without ADP) was determined with glutamate (10 $\mathrm{mM})$ plus malate $(2 \mathrm{mM})$ plus pyruvate $(5 \mathrm{mM})$, which activate the Krebs cycle enzyme malate dehydrogenase, providing NADH to the respiratory chain (complex I). Respiratory state 3 (coupled respiration) was determined in the presence of $\operatorname{ADP}(2.5 \mathrm{mM})$. Once the steady state was reached, the quality of mitochondria was assessed using a cytochrome $c$ test (16). If the increase in oxygen consumption was $>10 \%$ after the addition of $10 \mu \mathrm{M}$ cytochrome $c$, the experiments were excluded. The coupling of phosphorylation to oxidation was determined by calculating the respiratory control ratio as the ratio of state 3 to state 4 . Then, complex II was activated by succinate (10 $\mathrm{mM})$ addition. Addition of FCCP $(0.5 \mu \mathrm{M}$; a chemical-uncoupling molecule) was used to calculate the maximal respiratory capacity of mitochondria. To measure the respiration starting from complex II, rotenone $(0.5 \mu \mathrm{M})$ was added to inhibit the complex I activity. To determine the capacity of cytochrome $c$ oxidase (complex IV), antimycine A $\left(2.5 \mu \mathrm{M}\right.$; an inhibitor of Complex III) and $N, N, N^{\prime} N^{\prime}-$ tetramethyl- $p$-phenylenediamine $0.5 \mathrm{mM}$ plus ascorbate $(2 \mathrm{mM})$ were used as an artificial redox mediators that assist the transfer of electrons from ascorbate to cytochrome $c$. In the presence of ADP $(2.5 \mathrm{mM})$ and antimycine A $(5 \mu \mathrm{M})$, only complex IV respiration was stimulated. Because antimycine blocks electron transfer from complex III, the TMPD-related respiration rate may evaluate the complex IV-related maximal respiration rate, excluding complexes I, II, and III. Finally, sodium azide $(1 \mathrm{mM})$ was added for inhibiting complex IV and calculating the complex IV-related maximal respiration without autooxydation of TMPD-ascorbate itself. Analyses for the palmitoyl carnithine experiment was performed from fresh mitochondrial enrichment by the addition of $20 \mu \mathrm{M}$ of palmitoyl carnithine, and then coupled respiration was determined in the presence of $\operatorname{ADP}(2.5 \mathrm{mM})$. Rates of respiration are given in picomoles $\mathrm{O}_{2}$ per second per milligram protein. Data acquisition and analysis were performed with Datlab4 software (Oroboros).

Placental ATP and ADP measurements. Placental ATP and ADP measurements were determined using the ATP Colorimetric/Fluorometric Assay kit and the ADP Colorimetric/Fluorometric Assay kit (Abcam). Measurements were performed with the fluorometric assay, following the manufacturer's instructions, on $30 \mu \mathrm{g}$ of frozen placenta. ATP and ADP contents were measured in duplicate and calculated per microgram of tissue.

Statistical analysis. Results are reported as means \pm SE. Statistical analyses were performed using one-way ANOVA and a post hoc comparison with Dunnett's test. A $P$ value of $<0.05$ was considered significant. Analyses were performed using SigmaStat software (Systat Software).

\section{RESULTS}

Maternal and fetal parameters. At E21, maternal FR30 did not modify either litter size or sex ratio (Table 2). Food restriction (FR30) reduced maternal body weight by $39 \%(P<$ 0.001 ) and induced a fetal growth restriction, as reflected by

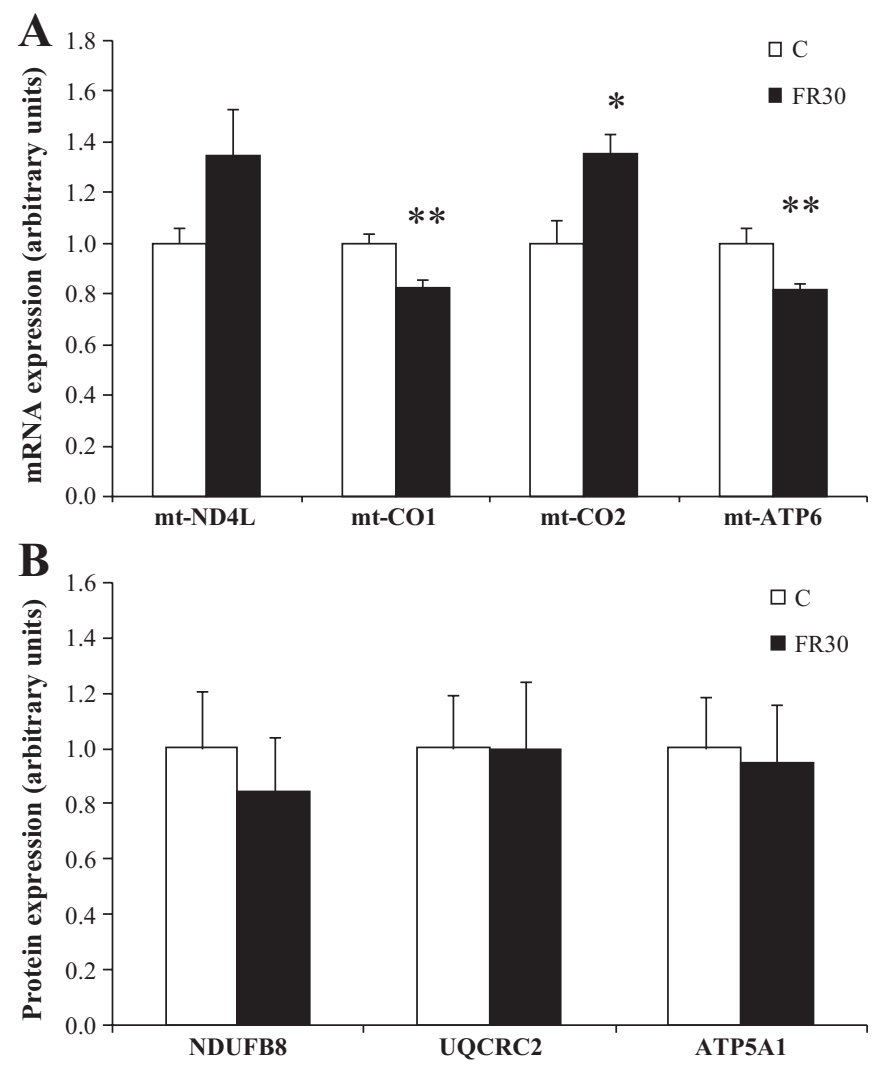

Fig. 3. Measurement of respiratory chain mRNA and protein expression. $A$ : relative quantification by RT-qPCR analyses of mtDNA-encoded RNA (C: $n=9$; FR30: $n=7-9$ ). $B$ : relative expression of respiratory chain proteins encoded by nuclear DNA. (C: $n=9$; FR30: $n=9$ ). $P<0.05$ vs. FR30 group. $* * P<0.01$ vs. FR30 group. 

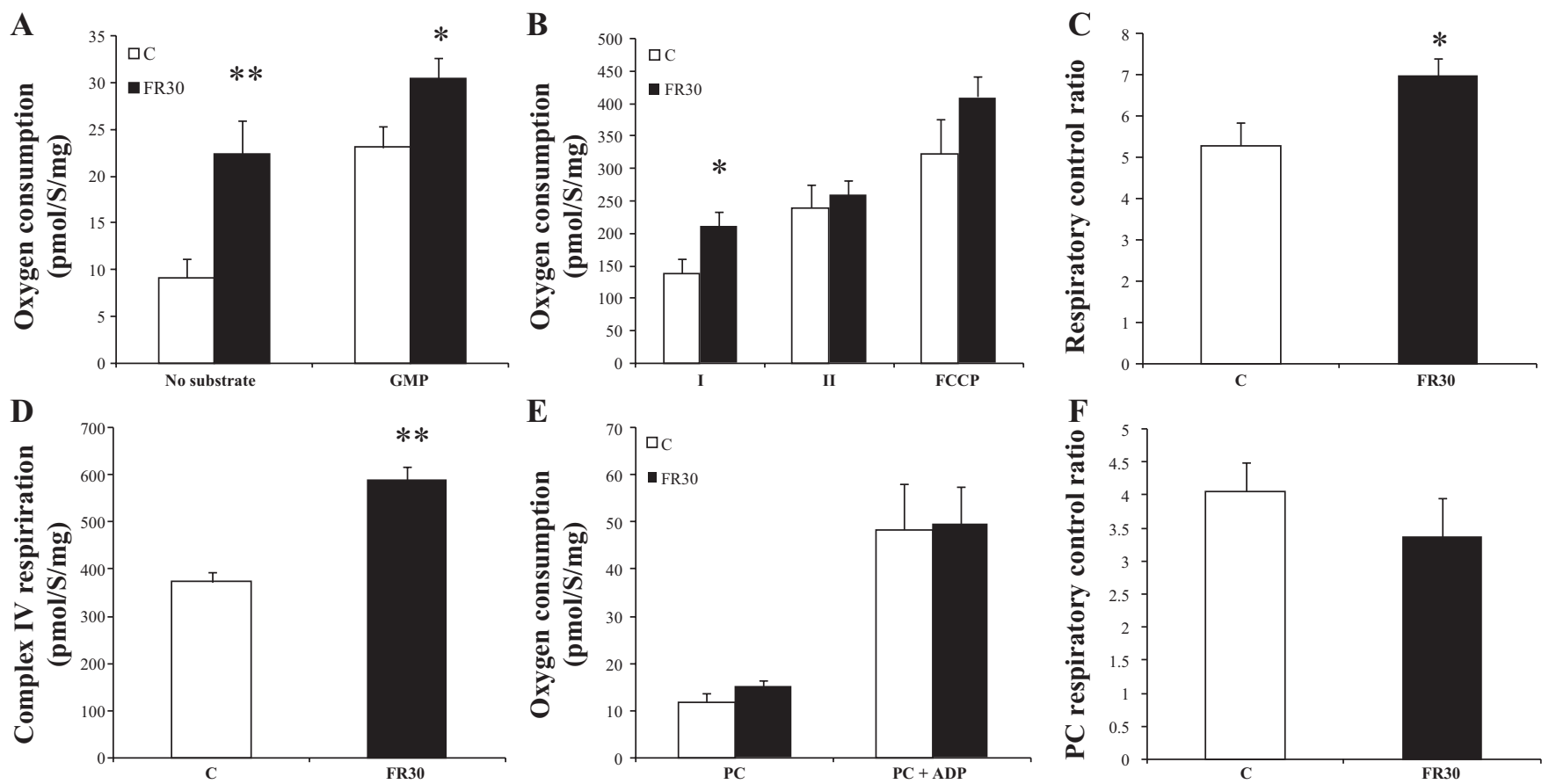

Fig. 4. High-resolution respirometry on enriched placental mitochondrial fraction. Measurement of placental mitochondrial respiration. A: without substrate or with substrate for complex I [glutamate malate pyruvate (GMP)]. B: in the presence of ADP with substrate for complex I (I) and/or complex II (II; succinate) and measurement of maximal mitochondrial respiration with a chemical uncoupling molecule (FCCP). $C$ : respiratory control ratio with GMP consumption. $D$ : complex IV respiration in the presence of an inhibitor of complex III (antimycine A) and an electron donor $\left(N, N, N^{\prime} N^{\prime}\right.$-tetramethyl-p-phenylenediamineascorbate). E: measurement of mitochondrial oxygen consumption in the presence of palmitoyl carnitine (PC) with or without ADP. $F$ : respiratory control ratio with PC consumption. $\mathrm{C}(n=5-8$ pools) and FR30 ( $n=5-6$ pools). $* P<0.05$ vs. FR30 group; $* * P<0.01$ vs. FR30 group.

decrease in length and weight of fetuses $(-9$ and $-29 \%$ respectively, $P<0.001$ ). The placental weight was decreased $(-25 \%, P<0.001)$. Maternal blood glucose level and plasma triglyceride and cholesterol levels were also decreased in FR30 rats. In FR30 fetuses, blood glucose level was decreased $(-42 \%, P<0.001)$.

Proteomic analysis of FR30 placentas. Protein profiles were analyzed using two-dimensional gel electrophoresis (2D-gel) coupled to mass spectroscopy. Figure $1 A$ shows a representative control 2D-gel profile. Comparative software-guided analyses of these gels revealed 14 differentially expressed spots identified using MALDI-TOF/TOF. Table 3 is a list of differentially expressed proteins with their calculated fold change relative to controls, $P$ values, both theorical and experimental isoelectric point and molecular weight, and subcellular location. As seen in Fig. $1 B$, it was particularly interesting that mitochondria are the most affected subcellular organelles. Figure $1 C$ is a tridimensional view of the control and FR30 2D-gel in which decreased expression of the most affected mitochondrial protein is indicated (SLC25A23, -1.69-fold change). Differential protein expression of SLC25A23 was verified by Western blotting ( -1.49 -fold change, $P=0.006)$.

$m t D N A$ analysis and mitochondrial $m R N A$ and proteins levels. mtDNA in FR30 placentas was strongly increased $(+250 \%, P<0.001)$ (Fig. 2A). Maternal FR30 increased the expression of three factors implicated in mtDNA replication, i.e., PPAR $\gamma$ coactivator- $1 \alpha$ (Pgc- $1 \alpha)$, nuclear respiratory factor 1 (Nrf1), and mitochondrial transcription factor A (Tfam) mRNA levels $(P<0.01, P<0.05$, and $P<0.001$, respectively; Fig. $2 B$ ). The expression of mitochondrial genes, including mt-Co1 $(-18 \%)$, mt-Co2 $(+38 \%)$, and mt-ATP6
$(-15 \%)$, was also modulated by FR30 (Fig. 3A). However, protein levels of NDUFB8, UQCRC2, and ATP5A1 were not affected (Fig. 3B).

Mitochondrial oxygen consumption determination. For highresolution respirometry analysis, a similar placental mitochondrial quantity from both groups was used (Fig. 4). Under basal conditions $(P<0.01)$ as well as after glutamate malate pyruvate (GMP) addition to activate the complex I $(P<0.05)$, FR30 mitochondria displayed a higher oxygen consumption (Fig. 4A). By adding ADP, the mitochondrial respiration was also increased $(P<0.05$; Fig. $4 B)$ by stimulating the complex I but not substrates of the complex II (Fig. $4 B$ ). In addition, the maximal respiration of FR30 group, using the uncoupling agent FCCP, was not significantly modulated (Fig. $4 B$ ). The respiratory control ratio was increased in FR30 placentas $(P<$ 0.05; Fig. 4C). Similarly, by stimulating the complex IV, a higher respiratory capacity of FR30 mitochondria was observed $(P<0.01$; Fig. $4 D)$. Using palmitoyl fatty acid as substrate, no difference was noted between groups (Fig. 4, $E$ and $F$ ).

mRNA levels of mitochondrial factors: ATP and ADP determination. Placental expression of several uncoupling proteins [UCP1, $-2,-3$, and -4 and BMCP1 (UCP5)] and two adenine nucleotide translocators (Ant1 and Ant2) was performed using qRT-PCR. mRNAs for UCP2, UCP3, UCP5, Ant1, and Ant 2 were detected. We found that UCP2 is the most expressed uncoupling protein. Placental mRNA level of UCP2 was reduced $(P<0.05$; Fig. $5 A)$, and those of adenine nucleotide translocators Ant1 $(+58 \%)$ and Ant2 $(-38 \%)$ were also affected by FR30 (Fig. 5B). The amount of placental ATP was decreased by $51 \%$ in the FR30 group $(P<0.001$; Fig. $5 C)$. 
A

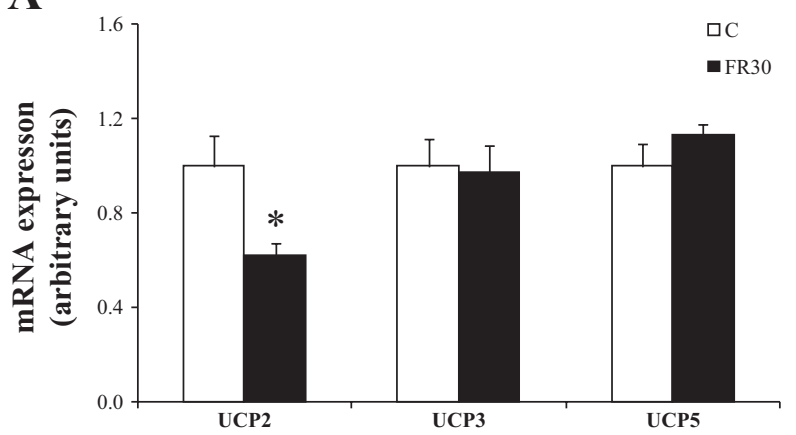

C

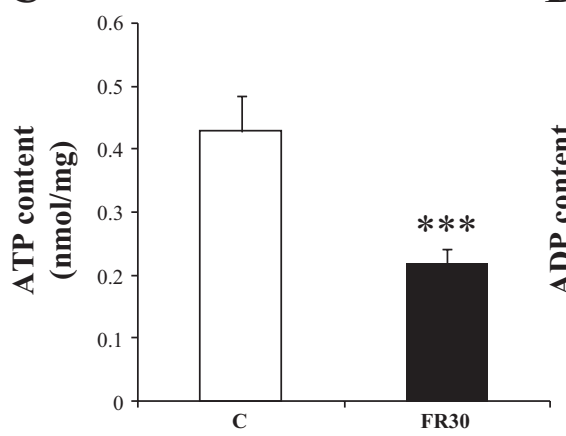

D

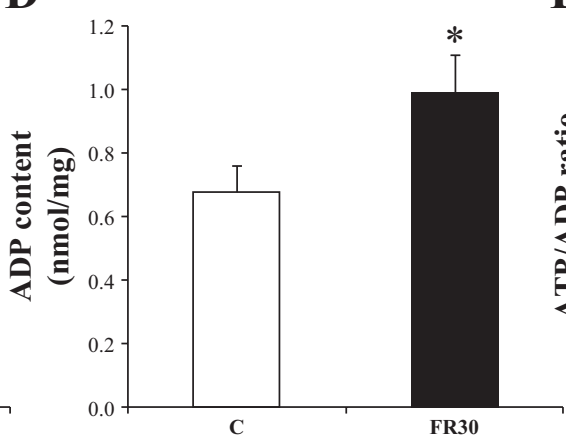

B

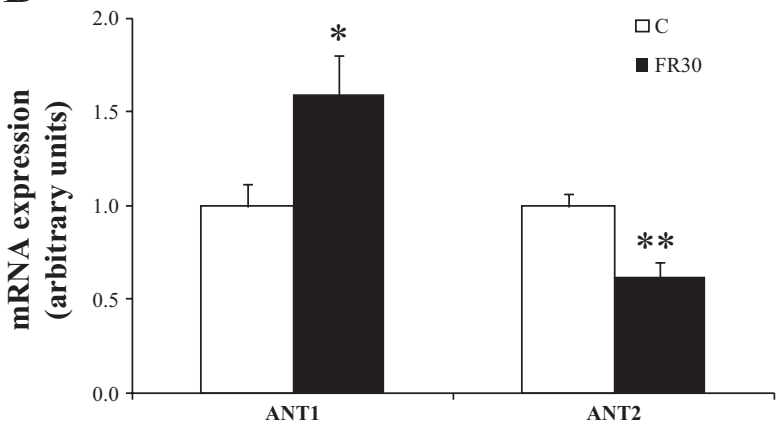

E

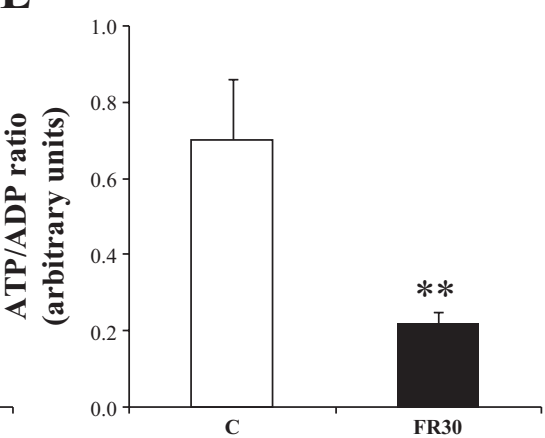

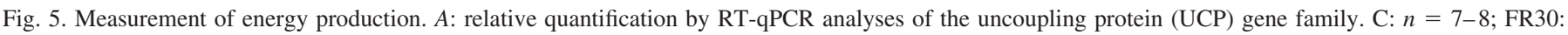

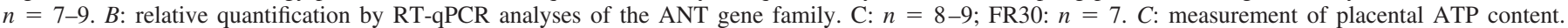

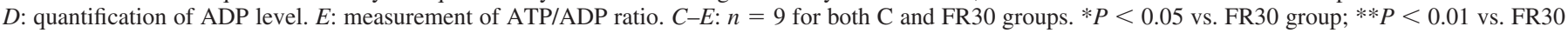
group; $* * * P<0.001$ vs. FR30 group.

In contrast, ADP content was increased $(P<0.05)$, and the ATP/ADP ratio was reduced drastically $(-70 \%)$ by maternal FR30 $(P<0.01$; Fig. 5, $D$ and $E)$.

\section{DISCUSSION}

In the present study, maternal FR30 drastically reduced both fetal and placental weights, demonstrating that maternal calorie restriction induces an intrauterine growth restriction in rats, as has been described previously with other maternal regimens (4, $19,23,24)$. To unravel the mechanisms of placental adaptation under this deleterious condition, we investigated the ways in which maternal food restriction had influenced the placental proteome.

Protein profiles were analyzed using two-dimensional gel electrophoresis coupled with mass spectroscopy to identify differentially expressed proteins. A total of 14 differentially expressed proteins were identified using MALDI-TOF/TOF analysis in this part of the placental proteome. We noted that the subcellular location of the most affected proteins was the mitochondrion. These data prompted us to investigate the changes in placental mitochondrial function induced by maternal FR30.

Few studies have investigated the physiology of mitochondria in the placenta, although these organelles play critical roles in both placental development and materno-fetal exchanges $(15,25)$. It has been proposed that placental mitochondrial dysfunction could be present in cases of placental insufficiency and may be critical in fetal programming (17). In mice, it was shown that impaired mitochondrial function in the embryo affects subsequent fetal and placental growth (34).
Here, we investigated the effect of maternal FR30 on placental mtDNA content, mitochondrial respiratory capacity, and expression of several mitochondrial genes and proteins. We found that placental mtDNA content was strongly increased by maternal FR30 and that the gene expression of Nrf1, Tfam, and PGC- $1 \alpha$, three genes implicated in mtDNA replication (11, 36), was also increased. These data suggest that maternal undernutrition may increase placental mitochondrial biogenesis, as has been reported in other tissues $(7,9,20)$. Then, we postulated that these disturbances may change the expression of the mitochondrial genome, and indeed we found a disturbed gene expression of several genes, including mt-co1, mt-co2, and ATP6. Because mtDNA genes exclusively produce proteins of the respiratory chain, we looked for a putative defective mitochondrial bioenergetic efficiency in FR30 placentas using high-resolution respirometry analysis.

Under basal conditions, FR30 mitochondria displayed higher oxygen consumption. This observation was also found after specific activation of the Krebs cycle and stimulation of the complex I but not complex II. Similarly, by stimulating the complex IV, a higher respiratory capacity of FR30 mitochondria was observed. These data demonstrated that the coupling of phosphorylation to oxidation was increased in FR30 placenta and revealed that the activity of the respiratory chain is increased by modulation of complex I and/or IV activities. However, using palmitoyl fatty acid metabolism as substrate, FR30 mitochondria did not display modulated respiratory capacity, showing an absence of modified capacity to fatty acid metabolism. Our findings demonstrated that the efficiency of the mitochondrial respiratory chain was increased under the 
FR30 condition potentially to maintain ATP production. In accord with our findings, we found that the expression of $\mathrm{UCP} 2$, an uncoupling protein that reduces the ATP production (37), was reduced by FR30 and that the expression of the adenine nucleotide translocator Ant1, which transfers ATP from the mitochondria to the cytoplasm (5), was increased but that the expression of Ant2 was decreased. Ant2's role would be to import into mitochondria ATP to maintenance of the membrane potential (8). Thus, the reduction of Ant2 in FR30 placental cells may thus increase the availability of ATP in the cytoplasm to sustain metabolic activities. For the first time, we reported here, using qRT-PCR, that several types of UCP proteins and two types of Ant are expressed in the placenta. In summary, FR30 triggers off molecular and metabolic mitochondrial adaptations in the placenta potentially to maintain cellular bioenergetic status when substrate's availability to the placenta is drastically reduced by maternal food restriction.

Using a comparable amount of placental extract, we found that both ATP content and ATP/ADP ratio were drastically reduced in FR30 placentas, showing that an impaired ATP synthesis occurs despite the previously described mitochondrial plasticity. Altogether, our data demonstrate for the first time a functional plasticity of mitochondria in the placenta. Under the FR30 condition, a marked increase in mitochondrial biogenesis occurs, and at a functional level, molecular adaptations ensure a higher efficiency of the mitochondrial respiratory chain. These adaptations have probably been mobilized by the drastic reduction in substrate availability and could constitute compensatory mechanisms to sustain the fetal growth under this deleterious gestational condition.

In conclusion, we provide first evidence that maternal undernutrition induces mitochondrial abnormalities in the placenta. Mitochondria are implicated in numerous critical functions for the fetoplacental development, such as ATP production for placental growth and transplacental nutrient transfers, reduction of oxidative stress, control of cell apoptosis, and production of hormones $(17,25,31,34)$. Mitochondrial defects may contribute to modify the placental activity, which may strengthen the effect of maternal undernutrition and thus be involved in the restriction of both fetal and placental growth. These hypotheses remain to be explored in this model. A causal linkage between placental mitochondrial defects and later-life diseases in offspring remains to be established. Interestingly, using the same experimental model, we reported previously that adult FR30 rats develop several pathologies, such as hypertension (29), an altered food intake behavior (6), and fat deposition (22), demonstrating the maternal FR30 program's long-term pathologies. Finally, mitochondrial compensatory mechanisms would likely be mobilized in several organs of FR30 fetuses, and we can postulate that fetal organ mitochondrial abnormalities might persist in adult FR30 rats. In accord with this hypothesis, long-term mitochondrial dysfunctions have been demonstrated in the pancreatic $\beta$-cells of rats prenatally exposed to a low-protein diet $(28,32)$. To conclude, growing evidence suggests that mitochondrial dysfunctions may be implicated in several metabolic diseases, such as type 2 diabetes (21), obesity (18), and vascular diseases (27), and our present findings suggest that placental mitochondrial defects may also be implicated in part in the etiology of fetal growth restriction.

\section{GRANTS}

This work was carried out with the financial support of the Agence Nationale de la Recherche/French National Research Agency under the Programme National de Recherche en Alimentation et nutrition humaine (Project No. ANR-06-PNRA-022).

\section{DISCLOSURES}

No potential conflicts of interest relevant to this article, financial or otherwise, are reported.

\section{AUTHOR CONTRIBUTIONS}

S.M., D.V., and J.L. did the conception and design of the research; S.M., S.L., N.T., M.-A.L., S.D., B.B., J.H., A.G., and J.L. performed the experiments; S.M., B.B., A.G., B.R., and J.L. analyzed the data; S.M. prepared the figures; S.M., R.C., C.B., A.G., L.S., B.R., C.J., D.V., and J.L. approved the final version of the manuscript; B.B. and J.L. interpreted the results of the experiments; R.C., C.B., L.S., B.R., C.J., and D.V. drafted the manuscript; R.C., C.B., L.S., B.R., C.J., D.V., and J.L. edited and revised the manuscript.

\section{REFERENCES}

1. Barker DJ. Maternal nutrition, fetal nutrition, and disease in later life. Nutrition 13: 807-813, 1997.

2. Barker DJ, Winter PD, Osmond C, Margetts B, Simmonds SJ. Weight in infancy and death from ischaemic heart disease. Lancet 2: 577-580, 1989.

3. Barker DJ, Osmond C, Thornburg KL, Kajantie E, Eriksson JG. The lifespan of men and the shape of their placental surface at birth. Placenta 32: 783-787, 2011.

4. Belkacemi L, Nelson DM, Desai M, Ross MG. Maternal undernutrition influences placental-fetal development. Biol Reprod 83: 325-331, 2010.

5. Brenner C, Subramaniam K, Pertuiset C, Pervaiz S. Adenine nucleotide translocase family: four isoforms for apoptosis modulation in cancer. Oncogene 30: 883-895, 2011.

6. Breton C, Lukaszewski MA, Risold PY, Enache M, Guillemot J, Rivière G, Delahaye F, Lesage J, Dutriez-Casteloot I, Laborie C, Vieau D. Maternal prenatal undernutrition alters the response of POMC neurons to energy status variation in adult male rat offspring. Am J Physiol Endocrinol Metab 296: E462-E472, 2009.

7. Cerqueira FM, Laurindo FR, Kowaltowski AJ. Mild mitochondrial uncoupling and calorie restriction increase fasting eNOS, akt and mitochondrial biogenesis. PLoS One 31: e18433, 2011.

8. Chevrollier A, Loiseau D, Stepien G. What is the specific role of ANT2 in cancer cells? Med Sci (Paris) 21: 156-161, 2005.

9. Civitarese AE, Carling S, Heilbronn LK, Hulver MH, Ukropcova B, Deutsch WA, Smith SR, Ravussin E; CALERIE Pennington Team. Calorie restriction increases muscle mitochondrial biogenesis in healthy humans. PLoS Med 4: e76, 2007.

10. Eriksson JG, Kajantie E, Thornburg KL, Osmond C, Barker DJ. Mother's body size and placental size predict coronary heart disease in men. Eur Heart J 32: 2297-2303, 2011.

11. Fernandez-Marcos PJ, Auwerx J. Regulation of PGC- $1 \alpha$, a nodal regulator of mitochondrial biogenesis. Am J Clin Nutr 93: 884S-890S, 2011.

12. Fowden AL, Forhead AJ. Endocrine regulation of feto-placental growth. Horm Res 72: 257-265, 2009.

13. Gluckman PD, Hanson MA, Cooper C, Thornburg KL. Effect of in utero and early-life conditions on adult health and disease. $N$ Engl J Med 359: 61-73, 2008.

14. Hochber Z, Feil R, Constancia M, Fraga M, Junien C, Carel JC, Boileau P, Le Bouc Y, Deal CL, Lillycrop K, Scharfmann R, Sheppard A, Skinner M, Szyf M, Waterland RA, Waxman DJ, Whitelaw E, Ong $\mathbf{K}$, Albertsson-Wikland K. Child health, developmental plasticity, and epigenetic programming. Endocr Rev 32: 159-224, 2011.

15. Jansson T, Myatt L, Powell TL. The role of trophoblast nutrient and ion transporters in the development of pregnancy complications and adult disease. Curr Vasc Pharmacol 7: 521-533, 2009.

16. Kuznetsov AV, Veksler V, Gellerich FN, Saks V, Margreiter R, Kunz WS. Analysis of mitochondrial function in situ in permeabilized muscle fibers, tissues and cells. Nat Protoc 3: 965-976, 2008. 
17. Leduc L, Levy E, Bouity-Voubou M, Delvin E. Fetal programming of atherosclerosis: possible role of the mitochondria. Eur J Obstet Gynecol Reprod Biol 149: 127-130, 2010.

18. Leloup C, Casteilla L, Carrière A, Galinier A, Benani A, Carneiro L, Pénicaud L. Balancing mitochondrial redox signaling: a key point in metabolic regulation. Antioxid Redox Signal 14: 519-530, 2011.

19. Lesage J, Blondeau B, Grino M, Bréant B, Dupouy JP. Maternal undernutrition during late gestation induces fetal overexposure to glucocorticoids and intrauterine growth retardation, and disturbs the hypothalamo-pituitary adrenal axis in the newborn rat. Endocrinology 142: 1692-1702, 2001.

20. López-Lluch G, Irusta PM, Navas P, de Cabo R. Mitochondrial biogenesis and healthy aging. Exp Gerontol 43: 813-819, 2008.

21. Lu H, Koshkin V, Allister EM, Gyulkhandanyan AV, Wheeler MB. Molecular and metabolic evidence for mitochondrial defects associated with beta-cell dysfunction in a mouse model of type 2 diabetes. Diabetes 59: 448-459, 2010.

22. Lukaszewski MA, Mayeur S, Fajardy I, Delahaye F, Dutriez-Casteloot I, Montel V, Dickes-Coopman A, Laborie C, Lesage J, Vieau D, Breton C. Maternal prenatal undernutrition programs adipose tissue gene expression in adult male rat offspring under high-fat diet. Am J Physiol Endocrinol Metab 301: E548-E559, 2011.

23. Mayeur S, Silhol M, Moitrot E, Barbaux S, Breton C, Gabory A, Vaiman D, Dutriez-Casteloot I, Fajardy I, Vambergue A, TapiaArancibia L, Bastide B, Storme L, Junien C, Vieau D, Lesage J. Placental BDNF/TrkB signaling system is modulated by fetal growth disturbances in rat and human. Placenta 31: 785-791, 2010.

24. McArdle HJ, Andersen HS, Jones H, Gambling L. Fetal programming: causes and consequences as revealed by studies of dietary manipulation in rats. Placenta 27: S56-S60, 2006.

25. Myatt L. Placental adaptive responses and fetal programming. J Physiol 572: 25-30, 2006.

26. Ravelli AC, van der Meulen JH, Michels RP, Osmond C, Barker DJ, Hales CN, Bleker OP. Glucose tolerance in adults after prenatal exposure to famine. Lancet 351: 173-177, 1998
27. Ren J, Pulakat L, Whaley-Connell A, Sowers JR. Mitochondrial biogenesis in the metabolic syndrome and cardiovascular disease. $J \mathrm{Mol} \mathrm{Med}$ (Berl) 88: 993-1001, 2010.

28. Reusens B, Theys N, Dumortier O, Goosse K, Remacle C. Maternal malnutrition programs the endocrine pancreas in progeny. Am J Clin Nutr 94: 1824S-1829S, 2011.

29. Rivière G, Michaud A, Breton C, VanCamp G, Laborie C, Enache M, Lesage J, Deloof S, Corvol P, Vieau D. Angiotensin-converting enzyme 2 (ACE2) and ACE activities display tissue-specific sensitivity to undernutrition-programmed hypertension in the adult rat. Hypertension 46: 1169-1174, 2005.

30. Robinson S, Walton RJ, Clark PM, Barker DJ, Hales CN, Osmond C. The relation of fetal growth to plasma glucose in young men. Diabetologia 35: 444-446, 1992.

31. Sewer MB, Li D. Regulation of steroid hormone biosynthesis by the cytoskeleton. Lipids 43: 1109-1115, 2008.

32. Theys N, Bouckenooghe T, Ahn MT, Remacle C, Reusens B. Maternal low-protein diet alters pancreatic islet mitochondrial function in a sexspecific manner in the adult rat. Am J Physiol Regul Integr Comp Physiol 297: R1516-R1525, 2009.

33. Thornburg KL, O'Tierney PF, Louey $\mathbf{S}$. The placenta is a programming agent for cardiovascular disease. Placenta 31: S54-S59, 2010.

34. Wakefield SL, Lane M, Mitchell M. Impaired mitochondrial function in the preimplantation embryo perturbs fetal and placental development in the mouse. Biol Reprod 84: 572-580, 2011.

35. Winder NR, Krishnaveni GV, Hill JC, Karat CL, Fall CH, Veena SR, Barker DJ. Placental programming of blood pressure in Indian children. Acta Paediatr 100: 653-660, 2011.

36. Wong LJ. Molecular genetics of mitochondrial disorders. Dev Disabil Res Rev 16: 154-162, 2010.

37. Yonezawa T, Kurata R, Hosomichi K, Kono A, Kimura M, Inoko H. Nutritional and hormonal regulation of uncoupling protein 2. IUBMB Life 61: 1123-1131, 2009. 